\title{
Variations in structural and plasmid profiles of starved Shigella in seawater
}

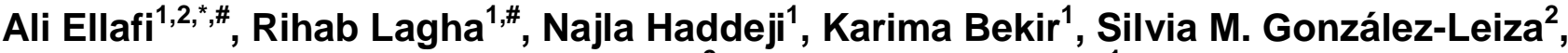 \\ Juan A. Ayala ${ }^{2}$ and Amina Bakhrouf ${ }^{1}$ \\ ${ }^{1}$ Laboratory of Analysis, Treatment and Valorization of Environment Polluants and Product, Faculty of Pharmacy, \\ Monastir University (Tunisia). \\ ${ }^{2}$ Centro de Biologia Molecular "Severo Ochoa", CSIC, Campus Cantoblanco, 28049, Madrid, Spain.
}

Accepted 10 May, 2013

\begin{abstract}
In this study, we incubated three strains of Shigella (Shigella sonnei (S1), Shigella boydii (S2) and Shigella flexneri (S3)) in seawater microcosms (at room temperature and at $4^{\circ} \mathrm{C}$ ) for eight months and we studied the modification of the proteins secreted, cytosolic and inner membrane profiles and their composition in fatty acids. Plasmid profiles were also investigated. Plasmids profiles analysis showed that S. boydii (S2) and S. flexneri (S3) did not lose any of their plasmids. In addition, fatty acids composition of Shigella under stress conditions was modified. Proteins secreted, cytosolic and inner membrane of stressed bacteria was changed and these modifications were manifested by the appearance and/or disappearance of bands.
\end{abstract}

Key words: Shigella, seawater, starvation, plasmids, proteins, fatty acids.

\section{INTRODUCTION}

In their natural environment, bacteria are constantly subjected to alternating between good growing conditions and conditions of stress or nutritional deficiencies which they must quickly adapt to survive. Indeed, enteric bacteria such as Shigella, disseminated in marine environment, are submitted to multiple physicochemical stresses: high osmolarity, low temperature, nutrient starvation (Moriarty and Bell 1993) and solar light irradiation (Arana et al. 1992). The ability of enteric bacteria to adapt to fluctuations in the ambient osmolarity is of fundamental importance for their survival (Nakamura et al. 1964; Bakhrouf et al. 1994; Ellafi et al. 2012).

In general, microorganisms do not respond to starvation by simply arresting all metabolic activities and stopping growth. Instead, they carry out starvationinduced activities that may include production of degradative enzymes, such as proteases and lipases, and substrate-capturing enzymes, such as glutamine synthetase and alkaline phosphatase. In addition, nutrient-deprived bacteria may try to differentiate into a more resistant state to maintain viability for starvation (Siegele and Kolter, 1992). During nutrient deficiency, bacteria can survive for a long time by sequential changes in cell physiology and gradual changes in morphology (Morita, 1993).

The mechanisms involved in the bacterial tolerance are not fully understood and the majority of studies are focused on the role of stress proteins and the regulation of gene expression in response to environmental changes (Foster and Spector, 1995; Foster, 2000; Dodd and Aldsworth, 2002). However, a link between the membrane fatty acid composition and the bacterial resistance has also been found (Annous et al., 1999; Sampathkumar et al., 2004; Alvarez-Ordonez et al., 
2008). In general, these authors have shown that cells with a decreased concentration of unsaturated fatty acids or with an increased content of saturated fatty acids have a decreased membrane fluidity, which is linked to a higher heat resistance. Furthermore, Alvarez Ordonez et al. (2008) found that the formation of cyclic fatty acids plays an important role in protecting acid-adapted Salmonella typhimurium cells from heat inactivation.

The aim of this work was to study the responses elicited in Shigella spp. following their incubation in seawater for eight months, by analyzing their: (i) secreted proteins, (ii) cytosolic and inner membrane profiles, (iii) membrane fatty acid profiles, and (iv) plasmid profiles.

\section{MATERIALS AND METHODS}

\section{Bacterial strains and growth conditions}

Three Shigella strains were used in this study: two Shigella sonnei (S1), Shigella boydii (S2) and Shigella flexneri (S3). All strains were provided from the Monastir hospital in Tunisia and maintained at $80^{\circ} \mathrm{C}$ in Luria-Bertani broth (LB) supplemented with glycerol $(15 \%$, $\mathrm{vol} / \mathrm{vol})$. For the experiments, the cells were grown at $37^{\circ} \mathrm{C}$ in tryptic soy broth (TSB, (Difco)) for $24 \mathrm{~h}$. Natural seawater $(100 \mathrm{ml})$ from the Tunisian coast of Monastir (salinity $4 \%, \mathrm{pH} 8$ ) was filtered through membranes (pore size, $0.22 \mu \mathrm{m}$; Millipore Corp., Bedford, Mass.) and autoclaved $\left(115^{\circ} \mathrm{C}\right.$ for $\left.15 \mathrm{~min}\right)$ in $100 \mathrm{ml}$ Erlenmeyer flasks. Shigella cells were washed three times by centrifugation (13000 rpm for $10 \mathrm{~min}$ at $20^{\circ} \mathrm{C}$ ) with autoclaved seawater and then suspended in $10 \mathrm{ml}$ of autoclaved seawater (Ellafi et al., 2009). The microcosms $(100 \mathrm{ml})$ were inoculated with these suspensions (approximately $10^{9} \mathrm{CFU} / \mathrm{ml}$ ) and then incubated in a static state at room temperature $\left(22\right.$ to $\left.25^{\circ} \mathrm{C}\right)$ and at $4^{\circ} \mathrm{C}$.

\section{Plasmid extraction and analysis}

Isolation of plasmid DNA was done using plasmid mini preparation kit obtained from Biobassic, according to the manufacturer's instruction. Plasmids were detected by electrophoresis in $0.7 \%$ agarose gel containing $0.5 \mu \mathrm{g}$ of ethidium bromide per milliliter and photographed with ultraviolet light illumination.

\section{Analysis of fatty acids}

To analyze the total cellular fatty acids, cells recovered from $10 \mathrm{ml}$ of each cell suspension were pretreated following the MIDI protocols (Sasser, 1990). All reagents for saponification, methylation, extraction, and washing were dispensed with autopipets into this same tube, making the hands-on time minimal. Next, the final extracts were analyzed by gas chromatography (column: $30 \mathrm{~m} \times 0.25 \mathrm{~mm}$ HP-Innowax; flame ionization detect temperature at $280^{\circ} \mathrm{C}$; carrier gas $\mathrm{N}_{2}$ at $1 \mathrm{ml} / \mathrm{min}$; injector temperature $270^{\circ} \mathrm{C}$; oven temperature programmed from 130 to $230^{\circ} \mathrm{C}$ ) using a Hewlett-Packard HP 5890 capillary gas chromatograph linked to an HP Chemstation integrator. The identification of fatty acid methyl esters was performed by external standards (all purchased from Sigma Chemical Co.) submitted to the same processes of manipulation as the biological samples analyzed. The values of fatty acids are presented as area percentage of total fatty acids. Total saturated fatty acids (SFA), total unsaturated fatty acids (UFA) were used to determine the differences among membrane fatty acids of Shigella cells grown under the different conditions. The UFA/SFA ratio was used as an indirect indicator of the membrane membrane fluidity. It has been previously reported that membranes with high UFA/SFA ratio show a high fluidity (Casadei et al., 2002).

\section{Extracellular proteins extraction}

Extracellular proteins of Shigella before and after incubation for eight months in seawater were prepared according to the method described previously (Kaniga et al., 1995). Briefly, the cells were grown at $37^{\circ} \mathrm{C}$ in tryptic soy broth prepared with seawater (100\%) to an optical density at $600 \mathrm{~nm}$ of 0.5 . Bacterial cells were removed from cultures by centrifugation at $7000 \times g$ for $20 \mathrm{~min}$ and subsequent filtration through a $0.22 \mu \mathrm{m}$ pore-size filter. Proteins from the cell-free culture supernatants were then precipitated by addition of $10 \%(\mathrm{v} / \mathrm{v})$ trichloroacetic acid and recovered by centrifugation at $7000 \times g$ for $20 \mathrm{~min}$. Pellets were resuspended in 4 $\mathrm{ml}$ of phosphate-buffered saline (PBS), and proteins were precipitated again by addition of $20 \mathrm{ml}$ of cold acetone. After centrifugation at $7000 \times g$ for $20 \mathrm{~min}$, the pellets were washed once with cold acetone, dried, and resuspended in $25 \mu \mathrm{l}$ of PBS.

Proteins secreted $(2 \mu \mathrm{g})$ were analysed by sodium dodecyl sulphate (SDS) polyacrylamide gel electrophoresis (PAGE) (Laemmli, 1970) with 15\% acrylamide in the separating gel and 5\% acrylamide in the stacking gel. After separation, the proteins were visualized according to standard procedures by staining with Coomassie brilliant blue G250 (Sigma, Chemical Co., St Louis, MO, USA) and molecular weights were determined by means of commercial markers (High-Range Rainbow; Amersham, Little Chalfont, Buckinghamshire, UK).

\section{Cytosol and inner membrane fractions}

The cytosol fractions were isolated as described previously (Kumar et al., 2001). Overnight cultures were centrifuged for $5 \mathrm{~min}$ at 7000 g. Pellets were washed once with $20 \mathrm{mmol} / \mathrm{L}$ Tris, $10 \mathrm{mmol} / \mathrm{L}$ EDTA, pH 8 (TE), then resuspended in the same buffer. Bacteria were disrupted by sonication for $1 \mathrm{~min}$, followed by a 2 min rest, then an additional 1 min sonication. Samples were centrifuged for 5 $\min$ at $7000 \mathrm{~g}$ to remove debris, and the resulting supernatant was centrifuged for $1 \mathrm{~h}$ at $60000 \mathrm{~g}$ at $4^{\circ} \mathrm{C}$. The clear supernatant was retained as cytosolic fraction. The pellet was resuspended in TE, and the protein concentration was estimated. Protein concentration was adjusted to $5 \mathrm{mg} / \mathrm{mL}$ and solubilized with sodium lauryl sarcosinate $1 \% \mathrm{w} / \mathrm{v}$ (final concentration) at $4^{\circ} \mathrm{C}$ for $1 \mathrm{~h}$. Samples were centrifuged again for $1 \mathrm{~h}$ at $60000 \mathrm{~g}$ at $4^{\circ} \mathrm{C}$, and the supernatant was taken for analysis of inner membrane fraction. Protein concentrations of cytosol and membrane fractions were estimated and analysed by sodium dodecyl sulphate (SDS) polyacrylamide gel electrophoresis (PAGE) (Laemmli, 1970) with $15 \%$ acrylamide in the separating gel and $5 \%$ acrylamide in the stacking gel.

\section{Statistical analysis}

Statistical analysis was performed using the S.P.S.S. 13.0 statistics package for Windows. The differences in UFA/SFA ratio were examined by the Friedman test, followed by the Wilcoxon signed ranks test. $\mathrm{P}$-values of $<0.05$ were considered as significant.

\section{RESULTS}

\section{Plasmid analysis}

Plasmid profiles of investigated Shigella strains analyzed 


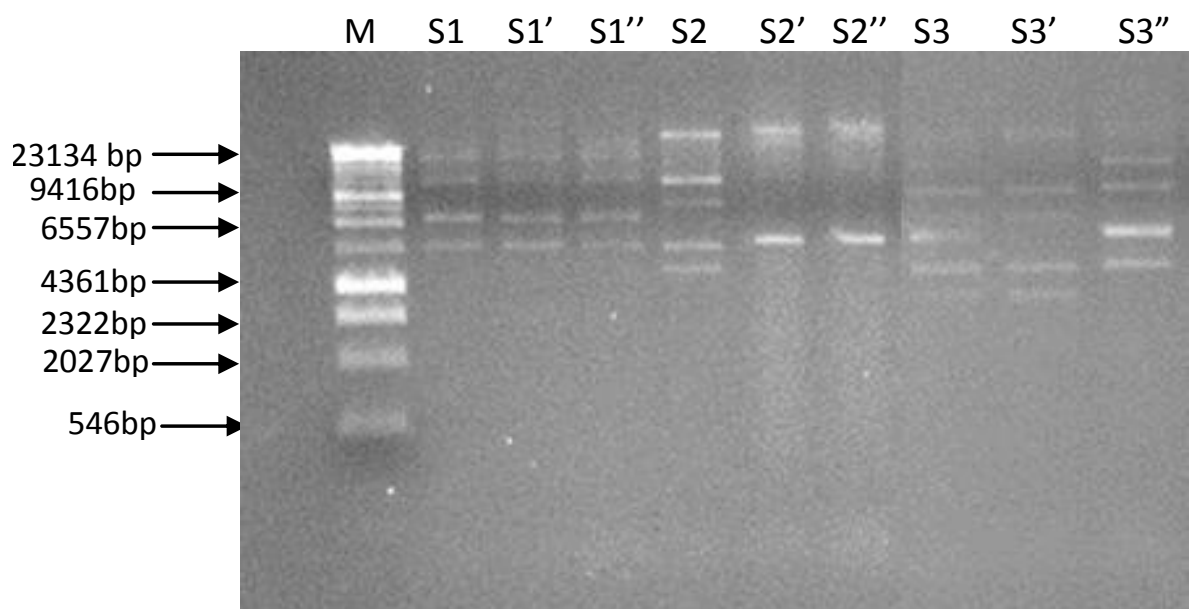

Figure 1. Plasmid DNA profiles of Shigella cells exposed to starvation for eight months in seawater. M, A DNA-HindllI molecular size marker (Promega); Sn, strain before incubation in seawater; Sn', strain incubated during eight months in seawater microcosms at room temperature. Sn", strain incubated during eight months in seawater at $4^{\circ} \mathrm{C}$.

Table 1. Fatty acids composition of Shigella exposed to starvation for eight months in seawater.

\begin{tabular}{lccccccccc}
\hline \multirow{2}{*}{ Strain } & \multicolumn{7}{c}{ Fatty acid } \\
\cline { 2 - 10 } & $\mathbf{C 1 0 : 0}$ & $\mathbf{C 1 2 : 0}$ & $\mathbf{C 1 4 : 0}$ & $\mathbf{C 1 4 : 1}$ & $\mathbf{C 1 5}: \mathbf{0}$ iso & $\mathbf{C 1 5 : 0}$ antieso & $\mathbf{C 1 6 : 1 \mathbf { n } 7}$ & $\mathbf{C 1 6 : 1 n 5}$ & $\mathbf{C 1 6}: \mathbf{0}$ \\
\hline S1 & 1.43 & 0.26 & 0.46 & 0.21 & 0.44 & 0.55 & 4.03 & 6.52 & 33.08 \\
S1' & 0.34 & 0.2 & 0.08 & - & 0.31 & 0.42 & 4.35 & 5.62 & 31.87 \\
S1" & 0.6 & 0.53 & 0.2 & 0.16 & 0.08 & 0.61 & 4.43 & 1.06 & 31.35 \\
S2 & 1.86 & 0.43 & 0.14 & 0.15 & 0.06 & 0.62 & 4.44 & 5.62 & 34.8 \\
S2' & 1.03 & 0.49 & 0.29 & 0.04 & 0.06 & 0.91 & 4.79 & 5.82 & 23.07 \\
S2" & 1.53 & 0.4 & 0.12 & 0.12 & 0.44 & 0.45 & 4.82 & 6.23 & 34.82 \\
S3 & 0.95 & 0.42 & 0.12 & - & 0.32 & 0.2 & 1.33 & 0.71 & 43.63 \\
S3' & 1.09 & 0.33 & 0.12 & 0.12 & 0.04 & 0.53 & 4.59 & 5.61 & 35.52 \\
S3" & - & - & - & - & - & 0.56 & 3.57 & 5.93 & 36.96 \\
\hline
\end{tabular}

on $0.7 \%$ agarose gel showed that all Shigella harbored four to six plasmids, ranging in size from 3 to $23 \mathrm{~kb}$ before incubation. After eight months of incubation in seawater, we also observed that $\mathrm{S} 1$ conserved its their plasmids. Furthermore, we noted that S2 and S3 lost its many original plasmids, which corresponds to $9,7.5$ and $4 \mathrm{~kb}$ sizes for S2 and $3 \mathrm{~kb}$ for S3 (at $4^{\circ} \mathrm{C}$ ), respectively, after this period of starvation (Figure 1).

\section{Membrane fatty acids composition of Shigella}

The membrane fatty acid composition of Shigella cultured under the different growth conditions (starved and normal cells) was determined using a chromatographic method (Tables 1 and 2). Twenty (20) fatty acids were found when cells were grown both under normal and stress conditions. The five main peaks were identified as palmitoleic acid (C16:1n7), n-hexadécanoique (C16: 1n5), paltmitic acid (C16:0), vaccenic acid (C18:1n7) and linoleic acid (C18:2n6). Their relative percentages were between 1.33 and $39.88 \%$. fifteen fatty acids were also detected at lower relative concentrations: C10:0, C12:0, C14:0, C14:1, C15:0 iso, C15:0 antieso, C17:0, C17:0 iso, C17 antieso, C17:1, C18:0, C18:1n9, C18:3n6, C20:1n9 and C20:0. As expected, incubation of Shigella in seawater resulted in differences in membrane fatty acid composition. Indeed, we also observed a significant $(\mathrm{P}<0.05)$ decrease in SFA accompanied by a significantly $(P<0.05)$ increase in the UFA. The UFA/SFA ratio observed for control cells (S1, S2 and S3) was higher $(1.05 ; 1.51 ; 1.43)$ than cells grown under stress conditions (Table 2).

\section{Extracellular proteins analysis}

After eight months of incubation in seawater, the 
Table 1. Contd.

\begin{tabular}{|c|c|c|c|c|c|c|c|c|c|c|c|}
\hline \multirow{2}{*}{ Strain } & \multicolumn{11}{|c|}{ Fatty acid } \\
\hline & C17:0 & C17:0 iso & C17:0 antieso & C17:1 & C18:0 & C18:1n9 & C18:1n7 & C18:2n6 & C18:3n6 & $\mathrm{C} 20: 0$ & C20:1n9 \\
\hline S1 & 0.31 & 1.16 & 0.43 & 0.91 & 1.14 & 1.11 & 24.44 & 20.34 & 2.31 & 0.52 & 0.23 \\
\hline S1' & 0.15 & 0.77 & 0.19 & 0.6 & 1.19 & 0.27 & 30.05 & 20.95 & 2.24 & 0.2 & 0.07 \\
\hline S1" & 0.86 & 0.93 & 0.5 & 0.93 & 1.27 & 1.88 & 31.43 & 20.01 & 2.71 & 0.16 & 0.19 \\
\hline S2 & 0.53 & 0.88 & 0.46 & 0.66 & 0.71 & 3.24 & 19.06 & 24.23 & 1.47 & 0.53 & - \\
\hline S2' & 0.45 & 1.33 & 0.94 & 1.97 & 3.33 & 2.35 & 31.34 & 14.92 & 5.72 & 0.55 & 0.5 \\
\hline S2" & 0.57 & 0.9 & 0.41 & 0.84 & 0.67 & 3.53 & 20.97 & 21.06 & 1.51 & 0.37 & 0.15 \\
\hline S3 & 0.65 & 0.88 & 0.13 & 0.24 & 0.86 & 0.71 & 2.47 & 39.88 & 1.26 & 0.43 & 4.7 \\
\hline S3' & 0.45 & 0.63 & 0.32 & 0.59 & 0.56 & 1.88 & 24.64 & 20.04 & 1.43 & 0.17 & 1.25 \\
\hline S3" & 0.2 & 0.59 & 0.31 & 0.3 & 1.03 & 0.27 & 20.62 & 26.3 & 1.19 & 0.01 & 0.05 \\
\hline
\end{tabular}

$\mathrm{Sn}$, Strain before incubation in seawater; Sn', strain incubated during eight months in seawater microcosms at room temperature. Sn", strain incubated during eight months in seawater at $4^{\circ} \mathrm{C}$. C10:0, Capric acid; C12:0, lauric acid; C14:0, myristic acid; C14:1, myristoleic acid; C15:0 iso, isopentadecylic acid; C15:0 antieso, antiesopentacyclic acid; C16:1n7, palmitoleic acid; C16:1n5, n-hexadécanoique acid; C16:0, palmitic acid; C17:0, margaric acid; C17:0 iso, isomargaric acid; C17:0 antieso, antiesomargaric acid; C17:1, heptadecenoic acid; C18:0, stearic acid; C18:1n9, oleic acid; C18:1n7, vaccenic acid; C18:2n6, linoleic acid; C18:3n6, gamma-linolenic acid; C20:0, arachidic acid; C20:1n9, eicosenoic acid.

Table 2. Effect of starvation on the fatty acids compostion Shigella.

\begin{tabular}{lccc}
\hline \multirow{2}{*}{ Strain } & \multicolumn{3}{c}{ Fatty acid } \\
\cline { 2 - 4 } & SFA & USF & USF/SFA \\
\hline S1 & 39.78 & 60.1 & 1.51 \\
S1' & $35.72^{*}$ & $64.28^{*}$ & $1.79^{*}$ \\
S1" & $37.09^{*}$ & $62.8^{*}$ & $1.69^{*}$ \\
S2 & 41.02 & 58.87 & 1.43 \\
S2' & $32.45^{*}$ & $67.45^{\star}$ & $2.07^{*}$ \\
S2" & $40.68^{\star}$ & $59.23^{*}$ & $1.45^{\star}$ \\
S3 & 48.59 & 51.3 & 1.05 \\
S3' & $39.76^{*}$ & $60.15^{*}$ & $1.51^{*}$ \\
S3" & $39.66^{*}$ & $58.23^{*}$ & $1.46^{*}$ \\
\hline
\end{tabular}

Sn: strain before incubation in seawater; Sn' :strain incubated during eight months in seawater microcosms at room temperature. Sn":strain incubated during eight months in seawater at $4^{\circ} \mathrm{C}$. SFA: Total saturated fatty acids; UFA: Total unsaturated fatty acids. ${ }^{*}: P<0.05$.

extracellular proteins of Shigella strains were examined by SDS-PAGE (Figure 2). Before their incubation in seawater, we found that all strains of Shigella had almost the same profile. Shigella secretes a large number of proteins in the extracellular medium. After eight months of incubation in seawater, we noticed a remarkable difference between the profiles of non-incubated and incubated strains. Indeed, we observed a decreased expression for almost all proteins compared to the normal state. At the profile $S$. sonnei (S1), we observed the appearance of four bands corresponding to molecular weights: $80,47,30$ and $25 \mathrm{kDa}$ and about the disap- pearance of two bands of size 22 and $57 \mathrm{kDa}$ after stress. We also noted the appearance of new bands after incubation in seawater for S2: 80, 40 and $37 \mathrm{kDa}$ and S3: $65 \mathrm{kDa}$. We also noted the disappearance of other bands of sizes 40 and $37 \mathrm{kDa}$ for S2 and 71 and $16 \mathrm{kDa}$ for S3.

\section{Cytosol and inner membrane analysis}

The proteins were fractionated and subjected to SDSPAGE. SDS-PAGE of the cytosolic and inner membrane is shown in Figures 3 and 4, respectively. Cytosolic fraction of Shigella grown in the starvation conditions showed significant difference. At the profile S1, we observed the appearance of two bands corresponding to molecular weights: 200 and $60 \mathrm{kDa}$ and about the disappearance of two bands of size 22 and $16 \mathrm{kDa}$ after stress. We also noted the appearance of new bands after incubation in seawater for S2: 15 and 5kDa and S3: 64, 22 and $4 \mathrm{kDa}$. We also noted the disappearance of other bands of sizes, 50 and $17 \mathrm{kDa}$ for S2 and for S3: 29kDa. The inner membrane fractions of normal and starved cells of Shigella did not show a significant difference (Figure 4).

\section{DISCUSSION}

The results in the present work show that Gram-negative bacteria like Shigella are able to adapt and survive under starvation conditions. Many marine bacteria, especially Shigella spp., can survive for a long time for starvation by sequential changes in cell physiology and gradual changes in morphology (Jiang and Chai, 1996). Our results show the starved cells of Shigella lose many their plasmids, only for S1. These results are in agreement with the report of Gauthier et al. (1988), who demonstrated 


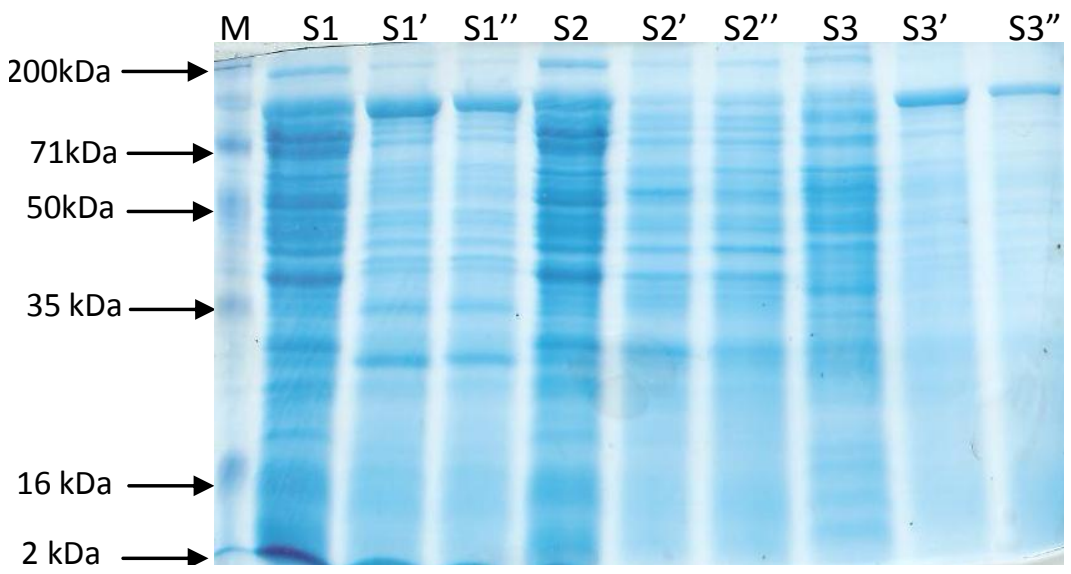

Figure 2. Extracellular proteins of Shigella cells exposed to starvation for eight months in seawater. M, molecular weight marker; Sn, strain before incubation in seawater; Sn', strain incubated during eight months in seawater microcosms at room temperature. Sn", strain incubated during eight months in seawater at $4^{\circ} \mathrm{C}$.

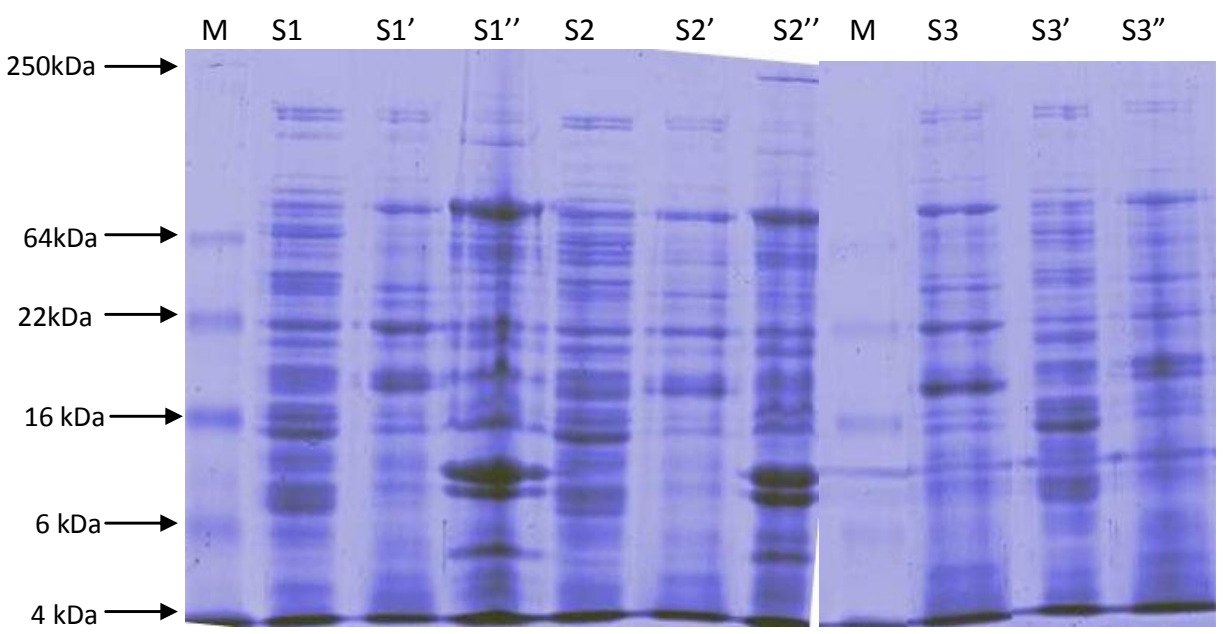

Figure 3. Cytosolic proteins of Shigella cells exposed to starvation for eight months in seawater. M, Molecular weight marker; Sn, strain before incubation in seawater; Sn', strain incubated during eight months in seawater microcosms at room temperature. Sn", strain incubated during eight months in seawater at $4^{\circ} \mathrm{C}$.

that Escherichia coli lost plasmid pCS1, encoding synthesis CFAI, after nine days of incubation in seawater. Our results testify to the genetic instability of stressed bacteria. Indeed, some marine bacteria can lose plasmid DNA in seawater while gaining others. This can reflect on the stability of virulence factors of bacteria in marine environment, as well as the transformation of nonpathogenic strain to pathogenic strain and vice versa.

Total saturated fatty acids (SFA) and total unsaturated fatty acids (UFA) were used to determine the differences among membrane fatty acids of Shigella cells grown under the different conditions. The UFA/SFA ratio was used as an indirect indicator of the membrane fluidity. A significant $(P<0.05)$ decrease in the UFA/SFA ratio was observed with all the serogroups. These changes in membrane fatty acid composition result in Shigella cells with decreased membrane fluidity. These results confirm those found by Ellafi et al. (2009) and Ali et al. (2011) on antibiotic resistance and morphological change after starvation in seawater. It has been previously reported that membranes with high UFA/SFA ratio show a high fluidity (Casadei et al., 2002). Various studies have indicated that growth conditions, such as the composition of the growth medium (Annous et al., 1999), the growth phase of the cells (Russell et al., 1995; Kadner, 1996; Casadei et al., 2002), the incubation temperature (Annous et al., 1999; Casadei et al., 2002; Kadner, 1996; Wang et al., 2005), and the pH value (Russell et al., 


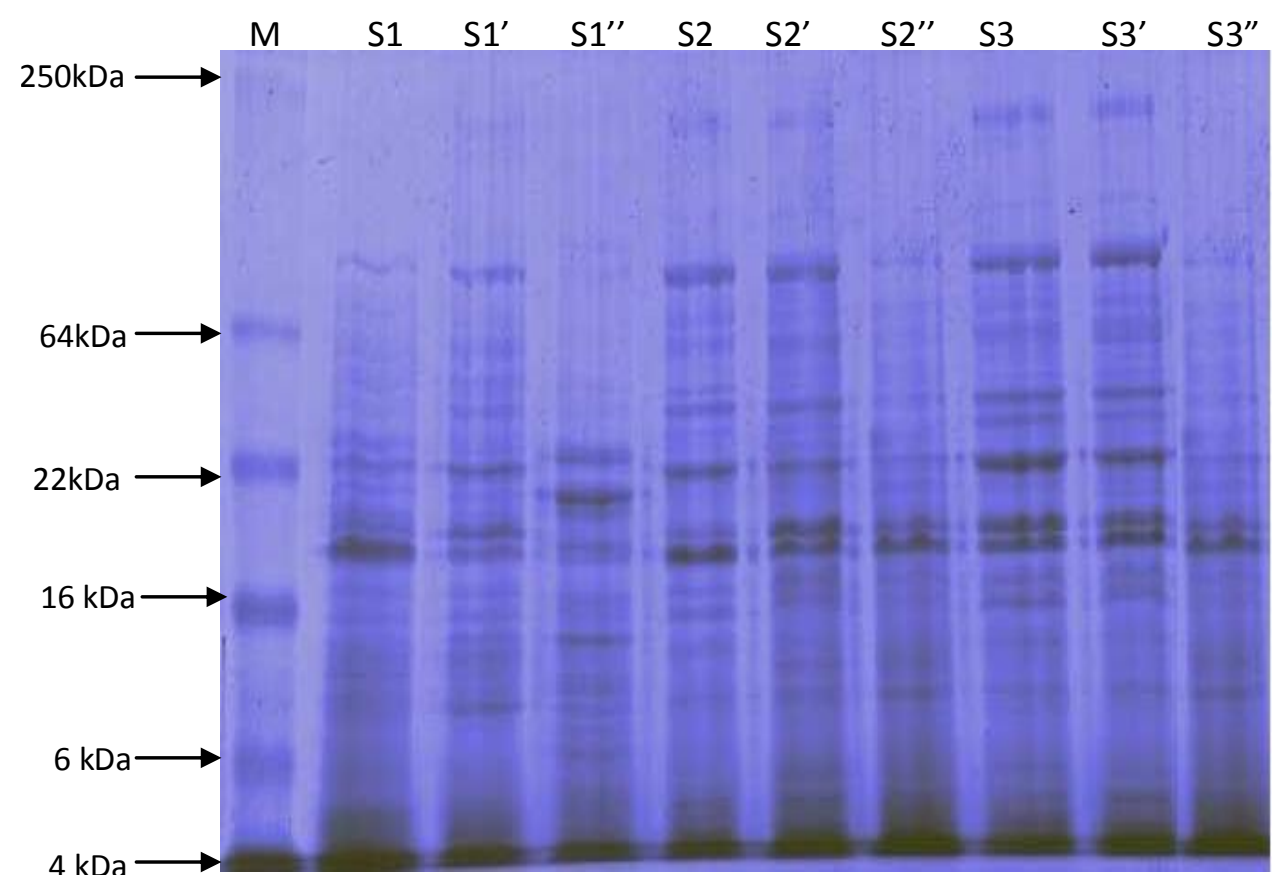

Figure 4. Inner membrane proteins of Shigella cells exposed to starvation for eight months in seawater. M, Molecular weight marker; Sn, strain before incubation in seawater; Sn', strain incubated during eight months in seawater microcosms at room temperature. Sn", strain incubated during eight months in seawater at $4^{\circ} \mathrm{C}$.

1995; Brown et al., 1997; Sampathkumar et al., 2004; Wang et al., 2005) markedly affect the bacterial membrane fatty acid composition. However, little is known on the influence of these modifications in membrane composition on the bacterial resistance to subsequent stresses. One of the most important consequences of membrane fatty acid changes in microorganisms is to modulate the activity of intrinsic proteins that perform functions such as ion pumping and nutrient uptake (Russell and Fukanaga, 1990).

Our study shows alterations in total proteins secreted and cytosolic patterns of starved Shigella cells after eight months of incubation in seawater microcosm. These alterations were manifested by the appearance and/or disappearance of bands as well as in the level expression of certain proteins. These modifications are probably due to nutrient deficiency in seawater. Indeed, it is clear now that changes in the environment induce several alterations in bacterial function and protein expression. After the beginning of an adverse effect, such as starvation, the synthetic functions of cells became inhibited and cells division is interrupted. In parallel, the production of several proteins increases (Kustos et al., 2007). These proteins include cytolysins, lipases, siderophores, exopolysaccharides, and proteases such as caseinase and gelatinase. These proteases are mainly involved in providing peptide nutrients for the microorganism. However, the production of bacterial proteases could contribute to the pathogenesis of infections, and therefore they could be considered virulence factors (Secades and Guijarro, 1999). The paucity of food in seawater can also lead to the loss of some features either by repression of the specific enzymes or following modifications at the level of the bacterial wall. The effect of environmental conditions on the production of extracellular proteolytic enzymes could play an important role in the induction or repression of the enzyme by specific compounds (Secades and Guijarro, 1999). Production of extracellular proteases has been shown to be sensitive to repression by different carbohydrate and nitrogen sources (Haulon et al., 1982). Catabolic enzymes responded to both carbon control and nitrogen control in enteric bacteria (Goldberg et al., 1976). In the bacteria A. hydrophila (O'Reilly and Day, 1983), A. salmonicida (Dalhe, 1971), and $P$. aeruginosa (Jensen et al., 1980) protease production is influenced by carbon and nitrogen sources. Additionally, the temperature can influence the protease production, as occurs in $A$. hydrophila (O'Reilly and Day, 1983).

In the present study, we observe that the starvation of Shigella could significantly influence the structural and plasmid profiles of the bacterium. This, in turn, may influence the pathogenesis of Shigella infections.

\section{REFERENCES}

Alvarez-Ordonez a, Fernandez, a, Lopez, M, Arenas, R, Bernardo (2008). Modifications in membrane fatty acid composition of 
Salmonella typhimuri in response to growth conditions and their effect on heat resistance. Int .J. Food. Microbiol. 123:212-219.

Ali Ellafi, Fethi Ben Abdallah, Rihab Lagha, Amina Bakhrouf (2011). Outer membrane proteins and morphological alterations of Shigella spp. under starvation in seawater. Afric. J. Microb. Res. 5(8):904-909.

Annous BA, Kozempel MF, Kurantz MJ (1999). Changes in membrane fatty acid composition of Pediococcus sp. strain NRRL B-2354 in response to growth conditions and its effect on thermal resistance. Appl. Environ. Microbiol. 65:2857-2862.

Bakhrouf A, Zaafrane S, Mzoughi R, (1994). Phenotypic alteration of Salmonella isolated from healthy carriers in seawater. Mar. Life. 4:38.

Brown JL, Ross T, McMeekin TA, Nichols PD (1997). Acid habituation of Escherichia coli and the potential role of cyclopropane fatty acids in low pH tolerance. Int. J. Food. Microbiol. 37:163-173.

Casadei MA, Mañas P, Niven G, Needs E, Mackey BM (2002). Role of membrane fluidity in pressure resistance of Escherichia coli NCTC 8164. Appl. Environ. Microbiol. 68:5965-5972.

Dalhe HK (1971). Regulation of the proteinase production in two strains of Aeromonas. Acta. Pathol. Microbiol. 79:739-746.

Dodd CER, Aldsworth TG (2002). The importance of RpoS in the survival of bacteria through food processing. Int. J. Food. Microbiol. 74:189-194

Ellafi A, Ben Abdallah F, Lagha R, Bakhrouf A (2012).Biofilm production, adherence and hydrophobicity of starved Shigella in seawater. Afric. J. Microb. Res. 6:4355-4359.

Ellafi A, Denden I, Ben Abdallah F, Souissi I, Bakhrouf A (2009). Survival and adhesion ability of Shigella spp. Strains after their incubation in seawater microcosms. World. J. Microbiol. Biotechnol. 25:1161-1168.

Foster JW (2000). Microbial responses to acid stress. In: Storz, G, Hengge-Aronis, R. (Eds.), Bacterial Stress Responses. ASM Press, Washington, DC. pp. 99-115.

Foster JW, Spector MP (1995). How Salmonella survive against the odds. Annu. Rev. Microbiol. 49:145-174.

Gauthier MJ, Munro PM, Breittmayer VA (1988). Damage to surface colonisation factors of enters adhesive Escherichia coli during starvation in seawater. Microbios. Lett. 38:37-45.

Goldberg RB, Bloom FR, Magasanik B (1976). Regulation of histidinase synthesis in intergenic hybrids of enteric bacteria. J. Bacteriol. 127:114-119.

Haulon GW, Hodges NA, Russell AD (1982). The influence of glucose, ammonium and magnesium availability on the production of protease and bacitracin by Bacillus licheniformis. J. Gen. Microbiol. 128:845851.

Jensen SE, Phillippe L, Teng TJ, Stemke GW, Campbell JN (1980). Purification and characterization of exocellular proteases produced by a clinical isolate and a laboratory strain of Pseudomonas aeruginosa. Can. J. Microbiol. 26:77-86.

Jiang X, Chai TJ (1996). Survival of Vibrio parahaemolyticus at low temperatures under starvation conditions and subsequent resuscitation of viable nonculturable cells. Appl. Environ. Microbiol. 62:1300-1305.

Kadner RJ (1996). Cytoplasmic membrane. In: Neidhasdt, F.C, Curtiss III, R, Ingraham, J.L, Lin, E.C.C, Low, K.B, Magasanik, B, Reznikoff, W.S, Riley, M, Schaechter, M, Umbarger, H.E. (Eds.), Escherichia coli and Salmonella: Cellular and Molecular Biology. ASM Press, Washington, DC. pp. 58-87.

Kaniga K, Trollinger D, Gala'N JE (1995). Identification of two targets of the type III protein secretion system encoded by the inv and spa loci of Salmonella typhimurium that have homology to the Shigella ipad and ipaa proteins. J. Bacteriol. 177:7078-7085.

Kumar SS, Sankaran K, Haigh R, Williams PH, Balakrishnan A (2001). Cytopathic effects of outer-membrane preparations of enteropathogenic Escherichia coli and co-expression of maltoporin with secretory virulence factor, EspB. J. Med. Microbiol. 50:602-612.

Kustos, I, Kocsis B, Kilár F (2007). Bacterial outer membrane protein analysis by electrophoresis and microchip technology. Exp. Rev. Proteomics. 4:91-106.

Laemmli UK (1970). Cleavage of structural proteins for the assembly of the head of bacteriophage T4. Nature 227:680-685.
Lowry OH, Rosebrough NJ, Farr AL, Randall RJ (1951). Protein measurement with the Folin phenol reagent. J. Biol. Chem. 193:265275.

Morita RY (1993). Bioavailability of energy and the starvation state. In: Kjelleberg $S$ (ed) Starvation in Bacteria. Plenum Press, New York, pp. 1-23.

Nakamura M, Stone RL, Krubsack JE, Pauls FP (1964).Survival of Shigella in seavvater. Nature. 203:213-214.

O'Reilly T, Day F (1983). Effects of culture conditions on protease production 422 by Aeromonas hydrophila. Appl. Environ. Microbiol. 45:1132-1135.

Russell NJ, Evans RI, ter Steg PF, Hellemons J, Verheul A, Abee T (1995). Membranes as a target for stress adaptation. Int. J. Food. Microbiol. 28:255-261.

Russell NJ, Fukanaga N (1990). A comparison of thermal adaptation of membrane lipids in psychrophilic and thermophilic bacteria. FEMS. Microbiol. Rev. 75:171-182.

Sampathkumar B, Khachatourians GG, Korber DR (2004). Treatment of Salmonella enterica serovar Enteritidis with a sublethal concentration of trisodium phosphate or alkaline $\mathrm{pH}$ induces thermotolerance. Appl. Environ. Microbiol. 70:4613-4620.

Sasser M (1990). Identification of bacteria by gas chromatography of cellular fatty acids, 1990: 1-7. MIDI technical note 101. MIDI, Inc. Newark, Del. pp. 1-7.

Secades P, Guijarro JA (1999). Purification and characterization of an extracellular protease from the fish pathogen Yersinia ruckeri and effect of culture conditions on production. Appl. Enviro. Microbiol. 65:3969-3975

Siegele DA, Kolter R (1992). Life after log. J. Bacteriol. 174:345-348.

Wang Y, Corrieu G, Beal C (2005). Fermentation pH and temperature influence the cryotolerance of Lactobacillus acidophilus RD758. J. Dairy. Sci. 88:21-29. 